\title{
EDUCAÇÃO PÚBLICA E POLÍTICA LIBERAL NO SISTEMA DE ENSINO DO BRASIL CONTEMPORÂNEO
}

\author{
Racquel Valério Martins ${ }^{1}$ \\ Lúcia Edriana de Sousa Cordeiro ${ }^{2}$ \\ Antonia Solange Pinheiro Xerez ${ }^{3}$
}

\begin{abstract}
Resumo:
Este artigo objetiva uma aproximação ao debate acerca da estruturação da escola pública no Brasil por meio de revisão bibliográfica que privilegia o viés histórico-político. A fundamentação teórica contempla a pedagogia histórico-critica e Saviani se constitui como a referência mais utilizada na primeira parte deste trabalho. A composição da escola pública é apresentada em sua relação intrínseca com o Estado moderno com base em um viés políticoeconômico compreendido como expressão da ordem social vigente na qual se potencializam capital e trabalho. O artigo é organizado com a intenção de torná-lo instrumento de diálogo com profissionais da educação que atuam na educação básica. Para tanto, procuramos apresentar e esclarecer, de modo pontual e sistemático, algumas reflexões que consideramos importantes para a compreensão da sociedade, do Estado e da escola que temos, de forma que possamos vislumbrar uma sociedade em que a escola pública possa servir aos interesses das camadas populares.
\end{abstract}

Palavras-chave: Sociedade. Liberalismo. Escola Pública.

\section{PUBLIC EDUCATION AND LIBERAL POLITICS IN THE CONTEMPORARY BRAZILIAN TEACHING SYSTEM}

\begin{abstract}
:
This study aims to discuss the structure of public schools in Brazil through a bibliographic review, considering both historical and political aspects. The research is based on historicalcritical pedagogy. Moreover, Saviani is the most used reference in the first part of the study. The structure of public schools is presented regarding its intrinsic relation to the modern State through political and economic elements. Such aspects are an expression of the current social order in which capital and work are intensified. Additionally, the study aims to become a dialogue tool for educational professionals that work in basic education. To do so, the research presents and explains systematically some important ideas for the comprehension of society, State, and school so we can glimpse a society where public schools suit the concerns of the popular classes.
\end{abstract}

Key Words: Society. Liberalism. Public schools.

\footnotetext{
${ }^{1}$ Instituto de Iberoamérica de la Universidad de Salamanca (USAL), racquelvm@gmail.com

${ }^{2}$ Mestre pelo Mestrado Acadêmico Intercampi de Educação e Ensino MAIE/UECE e professora da Escola de Educação Básica da SEDUC.

${ }^{3}$ Universidade Estadual do Ceará (UECE), antonia.xerez@uece.br
} 


\title{
EDUCACIÓN PÚBLICA Y POLITICA LIBERAL EN EL SISTEMA EDUCATIVO DEL BRASIL CONTEMPORÁNEO
}

\begin{abstract}
Resumen:
El objetivo de este artículo es debatir sobre la composición de la escuela pública en Brasil a través de una revisión de literatura, que privilegia em sesgo histórico-político. La base teórica contempla la pedagogía histórico crítica. Moreover y Saviani (1999), fue la referencia más utilizada en la primera parte de este trabajo. La composición de la escuela pública se presenta en su relación intrínseca con el estado moderno a partir de un sesgo político económico entendido como expresión del orden social actual en el que se pontencian capital y trabajo. El artículo está organizado con la intención de convertirlo en un instrumento de discusión para los profesionales de la educación que actúan en la enseñanza básica. Además, esta investigación presenta y esclarece ideas importantes para la comprensión de la sociedad, Estado y escuela que tenemos, para que podamos vislumbrar una sociedad en que la escuela pública pueda servir al interés de las clases populares.
\end{abstract}

Palabras clave: Sociedad. Liberalismo. Escuela pública.

\section{Introdução}

Para atender à proposta objetivada neste artigo, intentamos apresentar uma análise do livro "Escola e Democracia" de Saviani (1999) em que o autor faz uma exposição sobre as relações entre educação e política no contexto da sociedade moderna na qual se estabeleceu o Estado liberal e seu empreendimento de escola pública, elaborado em consonância com os interesses da classe burguesa.

Nessa obra, o autor divide as teorias educacionais conforme a relação que estas estabelecem com o problema da marginalidade. Essa relação é definida com base na concepção de educação e sociedade que cada teoria defende. A pedagogia tradicional e a pedagogia nova vão ser analisadas na relação conflituosa entre a proposta de educação, que serve aos interesses da burguesia, e o projeto que serviria para a classe trabalhadora.

Para dialogar com as análises da obra de Saviani (1999), buscamos, nos estudos de Romanelli (2014), fundamentos históricos para apresentar o processo em que o sistema de ensino no Brasil foi sendo construído enquanto uma política do Estado brasileiro. A abordagem inicia fazendo referência ao desenvolvimento da educação nos períodos colonial e imperial, e segue enfatizando os anos da República entre 1930 e 1970.

Na sequência, refletimos sobre o pensamento de Fernandes (2006), Prado Júnior (2006) e Mazzeo (2015) por concordarmos com a tese dos autores de que no Brasil não se desenvolveu uma burguesia revolucionária. Tal fato estaria internamente relacionado à formação colonial do 
país da qual se originou uma subordinação econômica e social e que, de algum modo, também produziu dependência nos âmbitos intelectual e cultural.

\section{Por uma pedagogia histórico-crítica}

De acordo com Saviani (1999), no que se refere à questão da marginalidade, as teorias educacionais podem ser classificadas em dois grupos: teorias que entendem a educação como instrumento de superação da marginalidade e teorias que pensam a educação como mecanismo de reforço da marginalização. As teorias do primeiro grupo são denominadas de "teorias nãocríticas" e as do segundo de "teorias crítico-reprodutivistas".

Para o primeiro grupo, a sociedade é concebida como essencialmente harmoniosa, sendo a marginalidade um fenômeno acidental que atinge indivíduos isoladamente. A educação surge como um instrumento autônomo para corrigir essa distorção. Por outro lado, o segundo grupo vê a sociedade dividida em classes sociais em que a marginalidade é um fenômeno inerente a essa estrutura. Nesse contexto, a educação é entendida como inteiramente dependente da estrutura social e cumpre a função de reforçar a marginalização.

Formam o grupo das teorias não-críticas: pedagogia tradicional, pedagogia nova e pedagogia tecnicista. Em contrapartida, o grupo das teorias crítico-reprodutivistas apresenta a seguinte composição: teoria do sistema de ensino enquanto violência simbólica, teoria da escola enquanto Aparelho Ideológico do Estado (AIE) e teoria da escola dualista.

As teorias não críticas acreditam ser possível resolver o problema da marginalidade na escola. As teorias crítico-reprodutivistas supõem que a escola é impotente para resolver o problema da marginalidade, pois na sociedade capitalista a função da escola é reproduzir a marginalização. Para a nossa abordagem, interessa-nos apresentar somente as reflexões do autor em torno da pedagogia tradicional e da pedagogia nova.

Conforme Saviani (1999), os sistemas nacionais de ensino começaram a ser organizados em meados do século XIX quando a burguesia se consolidava no poder. Por conta disso, para conservar sua dominação de classe, ela passa a desenvolver um modelo de sociedade fundamentado em uma democracia de caráter burguês segundo a qual um dos princípios básicos consiste na defesa de que a educação é direito de todos e dever do Estado.

Nesse quadro, a marginalidade é identificada com a ignorância atribuída aos ex-súditos do Antigo Regime ${ }^{4}$. Para que esses indivíduos se tornassem cidadãos livres na nova sociedade, fundada no contrato social, era preciso tomar o antídoto da instrução servido pela escola. Dessa

\footnotetext{
${ }^{4}$ O Antigo Regime é um sistema social e político que prevaleceu na Europa entre os séculos XV e XVIII, isto é, desde as descobertas marítimas até as revoluções liberais. Coincidiu politicamente com as monarquias absolutas, economicamente com o capitalismo social e socialmente com a sociedade de ordens.
} 
maneira, a escola surge com a função de transmitir os conhecimentos acumulados historicamente. Para desempenhar esse papel, ela vai contar com a figura do professor que, com disciplina, conduzirá as classes de alunos com lições e exercícios a serem assimilados.

Com o tempo, constatou-se que esse modelo de escola apresentava falhas e não conseguia atingir a universalização do ensino, pois nem todos ingressavam ou, com base nela, eram bem sucedidos. Muitos destes não aceitavam o tipo de sociedade protagonizado por essa escola. Assim, no final do século XIX, esse modelo passou a ser chamado de tradicional e a receber inúmeras críticas. Procurando superar essa visão, surgiram as ideias que vão dar origem à teoria da escola nova.

O movimento do "escolanovismo", advogou e estruturou a pedagogia nova. Segundo essa nova teoria, o marginalizado não é o ignorante, mas o rejeitado. Surge um processo de biopsicologização ${ }^{6}$ da sociedade, da educação e da escola em que a nova pedagogia passa a defender um tratamento diferencial. Assim, a marginalidade será corrigida pela contribuição da escola para construir uma sociedade capaz de respeitar as diferenças e as individualidades.

Desprendendo-se dos interesses de classes, a que ela tem servido, a educação [...] deixa de constituir um privilégio determinado pela condição econômica e social do indivíduo, para assumir um caráter biológico, com que ela se organiza para a coletividade em geral, reconhecendo a todo o indivíduo o direito a ser educado até onde o permitiam suas aptidões naturais, independente de razões de ordem econômica e social. (AZEVEDO et alii, 2010, p. 40).

Dessa forma, há um deslocamento de eixos entre a pedagogia tradicional e a pedagogia nova, dentre os quais se destacam os seguintes processos de transição: intelecto/sentimento; lógico/psicológico; conteúdo/método; esforço/interesse; disciplina/espontaneidade; diretivismo/não-diretivismo e quantidade/qualidade. Enfim, a substituição da pedagogia tradicional pela pedagogia nova é uma proposta que contempla a mudança "de uma pedagogia de inspiração filosófica centrada na ciência da lógica para uma pedagogia de inspiração experimental baseada principalmente nas contribuições da biologia e da psicologia" (SAVIANI, 1999, p. 21).

Para esse teórico, a pedagogia tradicional fundamenta-se em uma concepção filosófica essencialista enquanto a pedagogia nova é baseada em uma concepção filosófica existencialista.

\footnotetext{
${ }^{5} \mathrm{O}$ escolanovismo é um movimento de educadores europeus e norte-americanos, organizado em fins do século XIX, que propunha uma nova compreensão das necessidades da infância e questionava a passividade à qual a criança estava condenada pela escola tradicional. Tem seus fundamentos ligados aos avanços científicos da Biologia e da Psicologia.

${ }^{6}$ A biopsicologização diz respeito a uma prática de buscar explicações e soluções de todos os problemas escolares em uma perspectiva unidirecional e de abordagem clínica individualizada sem levar em conta todo o processo de produção social e política dos fenômenos.
} 
Na antiguidade grega, os filósofos clássicos defendiam que a essência humana só se realizava nos homens livres. Na idade média, a essência humana é atribuída a uma criação divina. $\mathrm{Na}$ modernidade, a essência vai ser associada à igualdade dos homens defendida pela burguesia.

O ideário escolanovista foi bastante divulgado, passando a ser defendido por muitos educadores. Serviu para melhorar a qualidade do ensino das elites, uma vez que suas escolas, por disporem de mais recursos, contavam com equipamentos melhores. Por outro lado, nas escolas das camadas populares, obteve-se um efeito contrário. A suavização da disciplina e da transmissão de conteúdos contribuiu para o rebaixamento do nível do ensino e a escola nova, para agravar o problema da marginalidade.

Ao enfatizar a qualidade do ensino ela deslocou o eixo de preocupação do âmbito político (relativo à sociedade em seu conjunto) para o âmbito técnicopedagógico (relativo ao interior da escola), cumprindo ao mesmo tempo uma dupla função: manter a expansão da escola em limites suportáveis pelos interesses dominantes e desenvolver um tipo de ensino adequado a esses interesses (SAVIANI, 1999, p. 22).

Com a ruptura do modo de produção feudal e a gestação do modo de produção capitalista, a classe burguesa iniciava seu processo de ascensão. Para tanto, dispôs-se a construir uma sociedade em que os homens sejam essencialmente livres para estabelecer relações contratuais que sirvam principalmente para regularizar as atividades de consumo (venda, compra, locação etc.). A burguesia utiliza-se do princípio da igualdade para propor um modelo social em substituição à injusta sociedade feudal em que a nobreza e o clero usufruíam de privilégios tidos como naturais ou de origem divina.

Esse é o fundamento jurídico da sociedade burguesa. Fundamento [...] formalista, de uma igualdade formal. No entanto, é sobre essa base de igualdade que vai se estruturar a pedagogia da essência e, assim que a burguesia se torna a classe dominante, ela vai [...] estruturar os sistemas nacionais de ensino e vai advogar a escolarização para todos (SAVIANI, 1999, p. 51).

A burguesia, ao se consolidar no poder, perdeu seu caráter revolucionário, de forma que seus interesses não visavam mais à transformação da sociedade e, sim, à sua conservação. A partir daí, a burguesia vai começar a propor a pedagogia da existência, uma vez que a pedagogia da essência não servia mais a seus interesses. Conforme sua nova proposta pedagógica, os homens não são mais essencialmente iguais, pois possuem diferentes características que vão definir particularidades como capacidade, aprendizagem, interesses e tantas outras.

Para Saviani (1999), a pedagogia da existência vai ter um caráter reacionário, legitimando as desigualdades, a dominação e os privilégios. A pedagogia tradicional ou da essência possuía um caráter revolucionário por sua concepção pedagógica igualitarista ao passo que a pedagogia nova ou da existência apresenta uma índole retrógrada à medida que, ao 
defender as diferenças, promove a justificativa das exceções. Dessa forma, o autor propõe uma pedagogia para além da essência e da existência:

Uma pedagogia revolucionária centra-se, pois, na igualdade essencial entre os homens. Entende, porém, a igualdade em termos reais e não apenas formais [...]. A pedagogia revolucionária é crítica. E por ser crítica, sabe-se condicionada. Longe de entender a educação como determinante das transformações sociais, reconhece ser ela elemento secundário e determinado. Entretanto [...] entende que a educação se relaciona dialeticamente com a sociedade. Nesse sentido, ainda que elemento determinado, não deixa de influenciar o elemento determinante [...]. A pedagogia revolucionária situa-se [...] numa proposta radicalmente nova. O cerne dessa novidade radical consiste na superação da crença seja na autonomia, seja na dependência absoluta da educação em face das condições sociais vigentes (SAVIANI, 1999, p. 75-76).

O autor acredita ser viável a elaboração de uma teoria educacional capaz de contribuir para a superação da marginalidade. Dessa forma, a escola passaria a ser pensada como uma realidade histórica, passível de ser modificada pelas ações do homem. Uma teoria educacional para combater a marginalidade deve ter como objetivo o estabelecimento de condições históricas favoráveis a um ensino de qualidade para as camadas populares.

Desde 1979, Saviani vem discutindo a estruturação dessa pedagogia e, a partir de 1984, passou a denominar sua teoria de "pedagogia histórico-crítica". Conforme Saviani e Duarte (2012), em sua teoria, os educandos são tidos como indivíduos concretos, vivendo em uma sociedade que exige o domínio do saber historicamente sistematizado. A tarefa da escola consiste em possibilitar o acesso aos conhecimentos elaborados pelos homens no tempo.

\section{Historicizando a educação pública no Brasil com base em um viés político-econômico}

Historicamente, o Brasil, de acordo com Romanelli (2014), não instituiu uma escola democrática. A educação brasileira seria o resultado de um debate ideológico que se estabeleceu entre as elites com base em seus interesses de classe. Isso aconteceu porque o Brasil se situa em uma condição específica de ser um país marcado por práticas políticas clientelistas ${ }^{7}$ resultantes de sua vinculação ao poder local, decorrendo daí a sua dificuldade para estruturar um sistema de ensino capaz de assegurar uma educação irrestrita para a nação.

Inicialmente, Romanelli (2014) explica que a sociedade organizada no Brasil, a partir do século XVI, não apresentava evidentemente nenhuma proposta de educação escolarizada para a ampla maioria da população, considerando que se tratava de um contexto histórico-social em que predominava o latifúndio e a escravidão. Dessa forma, o acesso ao saber formal era

\footnotetext{
${ }^{7} \mathrm{O}$ clientelismo era um subsistema de relação política com uma pessoa recebendo de outra a proteção em troca do apoio político. Também é chamado de política do favor. O clientelismo é, portanto, um sistema baseado em relações de troca que ocorreram em diversos momentos da história política brasileira, embora tenha sido durante o primeiro governo republicano que sua prática foi institucionalizada.
} 
restrito a um limitado grupo (filhos homens não primogênitos), pertencente aos segmentos aristocráticos. É importante lembrar que a base das desigualdades em nosso país foi engendrada desde a formação social escravista que

Desautoriza o liberalismo e a revolução em sua configuração clássica. Essa especificidade, determinada por tal concretude, não deixaria de gerar um Estado à sua imagem e semelhança. Um aparelho estatal de onde se despregue a violência e o favor deletério, para manter intacta sua estrutura fundamental, com as massas populares (escravos e homens livres) sempre fora do cenário político (MAZZEO, 2015, p. 108).

No contexto do período colonial, a atuação dos jesuítas definida pela Contrarreforma ${ }^{8}$ era recrutar fiéis para a Igreja Católica por meio da ação educativa catequética e escolar. A Companhia de Jesus $^{9}$ foi a responsável por uma formação cultural que valorizava as letras e as atividades literárias e acadêmicas ao mesmo tempo em que desprezava as atividades técnicas, artísticas, de pesquisa e de experimentação. O resultado dessa educação livresca foi o incentivo para a formação de uma pequena aristocracia letrada que passou a compor a camada mais elevada da hierarquia social da colônia brasileira.

[...] a classe dirigente, aos poucos, foi tomando consciência do poder dessa educação na formação de seus representantes políticos junto ao poder público. Os primeiros representantes da Colônia junto às cortes foram os filhos dos senhores de engenho educados no sistema jesuítico. Casaram-se, assim, portanto, a grande propriedade, o mandonismo e a cultura transplantada expandida pela ação pedagógica dos jesuítas (ROMANELLI, 2014, p. 36).

Encerrado o período de atuação dos jesuítas da colônia com sua expulsão em 1759, o houve uma desorganização total do ensino, só começando aos poucos a funcionarem as assim chamadas "aulas régias", classes isoladas que a Metrópole tentou instalar, na tentativa de assumir o encargo da educação na colônia, mas, conforme Romanelli (2014), a estrutura de ensino não se desfez em suas bases. Os mestres-escolas ${ }^{10}$ formados nos seminários foram os continuadores da ação pedagógica jesuítica.

O resultado foi que o ensino, sobretudo o secundário, acabou ficando nas mãos da iniciativa privada e o ensino primário foi relegado ao abandono, com pouquíssimas escolas, sobrevivendo à custa do sacrifício de alguns mestresescolas, que, destituídos de habilitação para o exercício de qualquer profissão rendosa, se viam na contingência de ensinar (ROMANELLI, 2014, p. 40-41).

\footnotetext{
${ }^{8}$ Reforma Católica criada em 1545 como resposta à Reforma Protestante de 1517, caracterizada principalmente pela reativação da Inquisição e o fortalecimento da Companhia de Jesus.

${ }^{9}$ Ordem religiosa fundada em 1534 por Inácio de Loyola. Pautava-se pela Ratio Studiorum, isto é, a "Regra de Estudos", que levava em conta o conhecimento do latim, das sagradas escrituras e de textos da tradição ocidental. Esse método foi de essencial importância na atmosfera do combate aos protestantes.

${ }^{10}$ Designa a posição de professor de instrução primária em uma escola.
} 
Com a vinda da família real portuguesa para o Brasil, em 1808, foram criados os primeiros cursos superiores ${ }^{11}$ no país com a finalidade de promover uma educação para a elite aristocrática. No entanto, não houve uma preocupação política para se estabelecerem as condições estruturais de um sistema de ensino nacional.

A nossa educação, estranha às realidades nacionais e tradicionalmente baseada no humanismo, correspondia à política educativa do Império, em que, emperrada na escola secundária, de tipo clássico, estritamente literário, o problema da educação nacional, nos seus dois aspectos fundamentais, das universidades e da educação popular, nunca se desprendeu de aspirações e fórmulas vagas (AZEVEDO et alii, 2010, p. 20).

O processo de descentralização do ensino, com a constituição republicana de 1891, estabeleceu que a União fosse responsável pelas instituições de ensino superior e secundário nos estados, enquanto estes ficariam responsáveis pela educação primária e pelo ensino normal. No entanto, o governo federal e os estados não desenvolveram um plano em conjunto, pois realizavam ações de forma independente, o que acabou gerando a construção de sistemas diferenciados de educação. O federalismo ${ }^{12}$ republicano acentuou as desigualdades regionais para além do plano econômico, atingindo também o campo educacional.

Ao analisar o sistema de educação do Brasil, Fernandes (1966 apud ROMANELLI, 2014) considera que o sistema republicano falhou ao não produzir modelos sistemáticos de educação para atenderem às exigências da sociedade capitalista, alicerçada na divisão de classes, na tecnologia científica e no regime democrático. Tal falha estaria relacionada ao fato de a sociedade brasileira ser incapaz de conduzir com coerência sua revolução burguesa.

As deficiências do sistema educacional brasileiro, tanto no que concerne à elasticidade da oferta quanto no que concerne à sua capacidade de criar uma demanda efetiva de educação, são, pois, muito mais graves na zona rural do que na urbana. E isso se explica, naturalmente, pela forma como se vem processando a chamada revolução burguesa no Brasil. O campo ainda não foi atingido, pelo menos em sua maior parte, pelas transformações nas relações de produção que o capitalismo introduz e conseguiu introduzir, com a industrialização na zona urbana (ROMANELLI, 2014, p. 87).

Romanelli (2014) propõe-se a analisar o problema da defasagem entre educação e desenvolvimento. $\mathrm{O}$ autor parte da compreensão de que esse processo se desenvolve conforme

\footnotetext{
${ }^{11}$ Em 11 de agosto de 1827, Dom Pedro I assinou um decreto imperial que criava dois cursos de direito no Brasil: um em Olinda (PE) e o outro em São Paulo (SP). As duas escolas formaram gerações de juristas, intelectuais e políticos brasileiros.

${ }^{12} \mathrm{O}$ Federalismo é a denominação de um sistema político em que municípios, estados e distrito federal, sendo independentes um do outro, formam um todo que valida um governo central e federal, que governa sobre todas as unidades acima citadas. Trata-se de um sistema de governo federativo em que vários Estados se reúnem para formar uma nação, cada um conservando sua autonomia.
} 
alterações no modelo econômico. Dessa forma, compreende que a expansão do ensino se configurou com base na influência exercida pelo desenvolvimento da Revolução Industrial ${ }^{13}$.

A educação pública, gratuita, obrigatória e leiga é uma conquista do Estado burguês, e surgiu na Europa com a ascensão da burguesia e o desenvolvimento da vida urbana. Historicamente, pois, é uma conquista resultante da decadência da antiga ordem aristocrática e, como tal, representa no Brasil, uma reivindicação ligada à nova ordem social e econômica, que começa a se definir mais precisamente após 1930 (ROMANELLI, 2014, p. 153).

Para Nagle (2009), nos anos de 1920, organizou-se um pensamento que combinava entusiasmo pela escolarização e otimismo pedagógico. Para o autor, o ideário liberal ${ }^{14}$ dos anos 1930 desenvolveu-se em um contexto histórico-social marcado por uma dualidade que consistiu primeiramente na passagem do sistema agrário-comercial para o sistema urbano-industrial, acompanhada da transição da sociedade estamental para uma sociedade de classes.

Nesse contexto, a escolarização passou a ser tratada como o único e maior problema a ser enfrentado pela nação brasileira para combater dificuldades financeiras e políticas. Nesse sentido, acreditava-se que "o sistema oligárquico se fundamenta na ignorância popular, de maneira que só a instrução pode superar este estado [...]” (NAGLE, 2009, p. 125).

Em 1924, no Rio de Janeiro, foi criada a Associação Brasileira de Educação ${ }^{15}$ (ABE) por um grupo de educadores influenciados por ideias vigentes na Europa e nos Estados Unidos, principalmente com base no pensamento de John Dewey ${ }^{16}$. A ABE realizou várias Conferências Nacionais de Educação para debater questões cruciais como gratuidade, obrigatoriedade, laicidade e Plano Nacional de Educação. Dessas discussões, resultou a publicação do Manifesto

\footnotetext{
${ }^{13}$ Processo de grandes transformações econômico-sociais que começou na Inglaterra no século XVIII e que se espalhou por grande parte do hemisfério norte durante todo o século XIX e início do século XX. A Revolução Industrial levou à substituição das ferramentas pelas máquinas, da energia humana pela energia motriz e do modo de produção artesanal pelo sistema fabril.

${ }^{14}$ A expressão "liberal" é, na Europa, atribuída aos pensadores ou políticos que defendem ideias de livre mercado e criticam a intervenção estatal e o planejamento. Já nos Estados Unidos, aplica-se a políticos ou a pensadores que apoiam a intervenção reguladora do Estado e a adoção de políticas de bem-estar social, geralmente ligados ao Partido Democrata.

${ }^{15}$ Grupo de intelectuais e profissionais vinculados à Escola Politécnica e ao Instituto Politécnico de Engenharia. Em 1932, a ABE lançou o célebre Manifesto dos Pioneiros da Educação Nova, redigido por Fernando de Azevedo. Como instituição voltada à educação e à cultura do país, a ABE hoje é procurada, com frequência, por estudiosos interessados em seu arquivo, considerado de utilidade pública no ano de 2008.

${ }^{16}$ Nome mais célebre da corrente filosófica que ficou conhecida como pragmatismo, embora ele preferisse o nome instrumentalismo - uma vez que, para essa escola de pensamento, as ideias só têm importância desde que sirvam de instrumento para a resolução de problemas reais.
} 
dos Pioneiros de $1932^{17}$, elaborado por Fernando de Azevedo ${ }^{18}$, com a parceria de vinte e seis educadores que assinam o documento.

O manifesto dos pioneiros da educação nova foi o resultado de um movimento pósrevolução de 1930. O manifesto apresenta pretensões liberais por meio de pontos articulados com o projeto varguista. Os pioneiros eram de vertentes teóricas diversas, sendo intelectuais que se investiam de uma função redentora. Eles se apresentavam como capazes de resolver o principal problema do Brasil por meio de uma reforma no campo da instrução, visto que as questões econômicas só poderiam ser resolvidas mediante profundas mudanças de caráter educacional.

Na hierarquia dos problemas nacionais, nenhum sobreleva em importância e gravidade o da educação. Nem mesmo os de caráter econômico lhe podem disputar a primazia nos planos de reconstrução nacional. Pois, se a evolução orgânica do sistema cultural de um país depende de suas condições econômicas, é impossível desenvolver as forças econômicas ou de produção, sem o preparo intensivo das forças culturais e o desenvolvimento das aptidões à invenção e à iniciativa que são os fatores fundamentais do acréscimo de riqueza de uma sociedade (AZEVEDO et alii, 2010, p. 33).

A ideia predominante no manifesto dos pioneiros era a de que a educação deveria acompanhar os avanços econômicos. Era um projeto de caráter nacionalista identificado com o pensamento liberal burguês da época. No entanto, em 1964, ocorreu a derrota do projeto nacional-desenvolvimentista.

O manifesto dos pioneiros, conforme Romanelli (2014), é um documento que apresenta suas proposições com base em uma concepção de indivíduo e não de classes. Por conta disso, defendia que o centro da ação pedagógica deveria ser o educando em sua relação com seus interesses, suas aptidões e tendências. A partir do ideário da Escola Nova ${ }^{19}$ de que a educação por si só é capaz de transformar a sociedade, o manifesto pensa a educação como um problema social cuja solução está diretamente relacionada com a promoção das condições para o desenvolvimento econômico do país.

A educação nova, alargando sua finalidade para além dos limites das classes, assume, com uma feição mais humana, sua verdadeira função social, preparando-se para formar a hierarquia democrática pela hierarquia das

\footnotetext{
${ }^{17}$ Propunha que o Estado organizasse uma escola única, pública, laica, obrigatória e gratuita. O movimento foi alvo da crítica da Igreja Católica que, naquela conjuntura, tinha sob seu controle parcela expressiva das escolas da rede privada.

${ }^{18}$ Redator do manifesto dos pioneiros da educação nova em 1932 em que se lançaram as bases e diretrizes de uma nova política de educação. Foi um dos expoentes do movimento da Escola Nova. Participou intensamente do processo de formação da universidade brasileira.

${ }^{19}$ Movimento de renovação do ensino, nascido na Europa e América do Norte, chegou ao Brasil em 1882 e exerceu grande influência nas mudanças promovidas no ensino na década de 1920. O movimento ganhou impulso na década de 1930 após a divulgação do Manifesto dos Pioneiros da Educação Nova (1932).
} 
capacidades, recrutadas em todos os grupos sociais, a que se abrem as mesmas oportunidades da educação (AZEVEDO et alii, 2010, p. 40).

O movimento renovador era contra a escola tradicional e não contra o Estado burguês, pois não questionava o contexto no qual pretendia implantar sua proposta de sistema educacional. A ordem social vigente não era combatida pelo movimento da Escola Nova. $\mathrm{Na}$ verdade, o que este buscava combater era a defasagem existente entre a situação econômica e social e a escola tradicional.

Um sistema de industrialização dependente, que importa tecnologia, evidentemente tem solicitações a fazer quanto à formação de recursos humanos para o trabalho especializado, mas tem poucas solicitações a fazer quanto à formação de pesquisadores e cientistas [...] O divórcio entre o ensino e a pesquisa no Brasil esteve, até certo ponto, coerente com o tipo de solicitação que o sistema econômico vinha fazendo a escola (ROMANELLI, 2014, p. 71).

De acordo com Fernandes (1975), as reformas educacionais realizadas no Brasil relacionam-se de modo histórico ao desenvolvimento de uma economia dependente. Ainda nas primeiras décadas do século XX, as elites brasileiras mostravam-se historicamente atrasadas por não defenderem um projeto de desenvolvimento vinculado à expansão da universidade. Tal modelo de universidade somente começaria a ser parcialmente desenvolvido depois da Revolução de 1930, com a ascensão de Getúlio Vargas ao poder.

Para que a universidade brasileira, conforme Fernandes (1975), do final dos anos de 1970, pudesse se renovar e se reconstruir, era preciso a implantação, em longo prazo, de uma democracia ampliada a partir da luta das classes trabalhadoras. Para o autor, o Brasil é um país que saiu da era colonial para a era nacional sem se libertar da subordinação econômica e cultural. Uma reforma universitária não seria suficiente para nos livrar dessa servidão, mas poderia ter sido um caminho para a conquista intelectual e política, condição para extinguir todas as formas de servidão, fossem elas impostas por elites externas ou internas.

Não precisamos da universidade como um bem em si, como um símbolo de progresso e de adiantamento cultural. Precisamos dela como um meio para avançarmos da periferia para o núcleo dos países que compartilham a civilização baseada na ciência e na tecnologia científica (FERNANDES, 1975, p. 33).

A reforma universitária elaborada pelos governos militares desenvolveu-se em concomitância com o processo de industrialização, que teve seu auge nas décadas de 1960 e 1970, batizado nas esferas desenvolvimento/subdesenvolvimento e na formação de um quadro econômico de dependência ao capital estrangeiro.

Para Fernandes (2006), o Brasil passou para o capitalismo sem passar por uma revolução, pois a burguesia brasileira de perfil colonial sempre apresentou resistência às 
organizações democráticas, pois a dominação de caráter local se deslocou, a partir de 1822, para um poder nacional, um regime burocrático de Estado nos moldes senhoriais.

Prado Júnior (2006) defende a tese de que a abolição desencadeou lentamente no Brasil um processo de mercantilização da economia com o desenvolvimento de relações tipicamente capitalistas. Apresenta uma conexão entre a independência política de 1822 e o processo de abolição em 1888. No entanto, considera que inexiste um projeto de nação, o que pode ser constatado com a política de incentivo à imigração.

O surgimento da burguesia brasileira como um transplante da burguesia imperial, ou seja, como o da mera transformação do senhor de engenho em burguês é uma explicação refutada por Fernandes (2006). Dessa forma, defende que a burguesia brasileira não se desprendeu nem se opôs às camadas senhoriais, já que elas iriam operar a estruturação do sistema capitalista no Brasil de forma que seus privilégios fossem mantidos.

No contexto do capitalismo mundial, de acordo com Fernandes (2006), o Brasil assumiu a posição de um país colonizador e escravocrata do qual se originou uma burguesia associada e subordinada aos centros hegemônicos do capital. Dessa forma, as camadas senhoriais brasileiras se apropriaram do Estado e marcaram a política por um domínio patrimonialista e clientelista.

A inexistência de condições históricas que direcionassem a uma ruptura concreta, de cunho revolucionário, com a estrutura socioeconômica colonial, possibilita à burguesia latifundiária que assuma o processo da independência e, posteriormente, crie um aparelho de Estado, dentro de suas diretrizes ideológicas, com o cuidado permanente de afastar quaisquer iniciativas que apontassem para o perigo de transformações mais radicais (MAZZEO, 2015, p. 83).

Nessa sequência, conforme Prado Júnior (2006), o advento da República não passou de um golpe militar com a colaboração de alguns poucos grupos civis e sem nenhuma participação popular. A República rompeu com um conservadorismo artificial, que tinha suas raízes na cultura religiosa predominantemente católica existente no Brasil no período imperial, que consistia em condenar o desejo de prosperidade material. O homem de negócios que tinha o objetivo de enriquecer era mal visto durante o império, mas passou a ser valorizado no período republicano quando a defesa dos interesses privados se tornou um dos principais eixos das atividades políticas.

A dependência da economia brasileira, conforme Prado Júnior (2006), é um fato que se prende às raízes da formação do país. O Brasil foi essencialmente uma economia colonial de exportação constituída para fornecer gêneros alimentícios e matérias-primas tropicais, em oposição ao que denominaríamos de economia "nacional", que seria a organização da produção 
em função das necessidades próprias da população que dela participava. Sendo assim, o passado da economia de caráter colonial foi a circunstância principal que tornou o Brasil tão vulnerável à penetração do capital financeiro internacional quando o capitalismo chegou a essa fase do seu desenvolvimento.

A raiz da crise econômica situa-se na contradição alicerçada entre capital e trabalho, pois, ao mesmo tempo em que o capitalismo atinge o seu estágio mais avançado, trazendo profundas transformações no processo produtivo, derivadas da revolução técnico-científica, aumenta os setores parasitários (representantes do sistema financeiro), diminuindo a utilização de mão de obra produtiva e fazendo crescer o desemprego estrutural e a precarização das condições de trabalho e de vida dos trabalhadores.

Nesse sentido, vem se organizando um desmonte da escola pública promovida pelo massacre do capital. Conforme Sousa Júnior (2014), no atual contexto histórico, o capital se volta contra os mecanismos democráticos obrigando os Estados nacionais a se curvarem diante de seus interesses financeiros. As consequências dessa dinâmica capitalista é a deterioração da vida social por meio do desemprego, da indigência e da exclusão social.

O principal problema que se coloca para a escola é o de compreender, em primeiro lugar, que toda a ofensiva do capital, que se dá a partir do final dos anos 1960, início dos anos 1970, tem colocado em questão justamente a dimensão mais positiva da escola, suas promessas e possibilidades efetivas de democratização (SOUSA JÚNIOR, 2014, p. 207).

O papel do Estado vai sendo redefinido nesse momento em que o capitalismo não mais consegue dar ao capital excedente um destino lucrativo. Conforme Mészáros (2000 apud SANTOS, 2017), o sistema capitalista hoje, mais do que nunca, para continuar acumulando e protegendo seus lucros, não pode dispensar a parceria do Estado. Assim, a partir dos anos 1980, o Estado brasileiro vem assumindo compromissos junto a organismos financeiros, como o Fundo Monetário Internacional (FMI) e o Banco Mundial.

O verdadeiro objetivo do Banco Mundial é proporcionar o fomento necessário à manutenção de uma certa taxa de crescimento dos chamados países em desenvolvimento, que resultasse no cumprimento das metas de sustentabilidade econômica e na garantia que esses países tomadores de empréstimos efetuem o pagamento de suas dívidas externas [...] Contudo, o agravamento da crise do endividamento nos países periféricos, a partir de 1980, abre espaço ao Banco Mundial e ao conjunto dos organismos multilaterais de financiamento para desempenhar o papel de agentes no gerenciamento das relações de crédito internacional e na definição de políticas de reestruturação econômica, por meio de programas de ajuste estrutural (MENDES SEGUNDO, 2005, p. 46-47).

A Conferência Mundial sobre Educação para Todos foi realizada em 1990, em Jomtien, na Tailândia. Esse evento foi organizado pelo Banco Mundial, pelo Programa das Nações Unidas pelo Desenvolvimento (PNUD), pelo Fundo das Nações Unidas para a Infância 
(UNICEF) e pela Organização das Nações Unidas para a Educação, Ciência e Cultura (UNESCO). Conforme Mendes Segundo (2005), o objetivo da Conferência era formular diretrizes de uma política educacional para países em desenvolvimento, os quais se encontravam em grande endividamento junto ao capital financeiro representado pelo FMI e Banco Mundial.

De acordo com Martins (2019), no Brasil, conseguiu-se alcançar crescimento econômico, mas limitado a poucos setores e sujeito a crises econômicas conjunturais e endividamento, afastando-se de um modelo de desenvolvimento econômico, não tendo ocorrido nenhum plano ambicioso para modificar o panorama das escolas públicas, apesar da estrutura do ensino superior do Brasil revelar excelência em ensino e pesquisa em determinados segmentos.

Após a democratização, mais precisamente ao iniciar o projeto neoliberal durante a década de 1990, o Brasil parece ter absorvido muito mais os aspectos nocivos da desregulamentação da economia do que aquilo que foi preconizado como os fatores benéficos que acompanham a ideologia neoliberal. A rapidez da abertura econômica e do processo de privatizações não foi acompanhada por um redirecionamento das funções básicas do Estado.

Ademais, não podem ser esquecidos os muitos retrocessos após o referido período, no qual ganharam destaque os projetos de lei da Escola sem Partido, os quais desconsideram o que foi construído durante a recente experiência democrática, como os espaços de diálogos entre toda a comunidade educativa e alegam que a qualidade da educação brasileira estaria comprometida por uma suposta doutrinação ideológica de esquerda, nos últimos vinte ou trinta anos, e que isso era o que inviabilizava o estudo dos conteúdos escolares necessários a um bom desempenho em exames de larga escala, e omitem a história de escolarização tardia que teve o Brasil (ROSA, 2018).

Vale ressaltar que a educação para o crescimento econômico se oporá à presença das artes e das humanidades como ingredientes da formação básica e, como alternativa frente a tal modelo, está o conhecido paradigma do desenvolvimento humano, modelo que reconhece que todas as pessoas gozam de uma dignidade humana inalienável que deve ser respeitada pelas leis e instituições.

\section{Considerações Finais}

Ao finalizarmos a presente exposição, destacamos algumas notas conclusivas. Primeiramente, compreendemos que a pedagogia liberal burguesa apresenta limites para o projeto de expansão da escola pública. A burguesia se apropriou da teoria da escola nova para 
fazer prevalecer seus interesses de classe e, nisso, convenceu segmentos populares com a ilusão do modelo liberal de escola.

Concordamos com a teoria da pedagogia histórico-crítica para promover a construção histórica de uma escola comprometida com a democratização do conhecimento. Identificamonos com o cerne dessa proposta, que consiste na superação da crença, seja na autonomia, seja na dependência absoluta da educação em face das condições sociais vigentes. Amparados pela pedagogia histórico-crítica, contamos com a possibilidade de a escola poder contribuir para o combate à marginalidade social.

Somos partidários da ideia de que o Brasil ainda não instituiu um sistema de ensino plenamente democrático por duas razões. A primeira é a de que a burguesia brasileira não se prontificou a fazer tal sistema, devido a seu caráter atrasado, em virtude da subordinação antes colonial e hoje imperialista. O segundo fator é que as camadas populares e progressistas ainda não se organizaram suficientemente para a luta por uma educação pública de qualidade irrestrita.

A preocupação do liberalismo clássico consiste no estabelecimento de uma teoria para justificar um governo legítimo. O surgimento do Estado é explicado para garantir a conservação dos direitos naturais dos indivíduos: a propriedade, a liberdade, a igualdade, a segurança e a vida. No Brasil, parece-nos que o termo liberalismo, que recentemente vem sendo bastante empregado, sempre foi mais alusivo à defesa da propriedade (juntamente com os direitos individuais).

As condições históricas no Brasil enviesaram o pensamento liberal de maneira que o Estado brasileiro se formou menos condicionado pelas diretrizes ideológicas do liberalismo e mais identificado com as práticas clientelistas enraizadas na sociedade colonial escravista, que foram mantidas no Império e ganharam a República.

Por conta da crise de caráter internacional do capitalismo imperialista, nas últimas décadas do século XX, o capital, para se manter, inicia um movimento para implementar medidas extremas cujos objetivos são os de reduzir serviços públicos (educação, saúde, segurança), salários, direitos trabalhistas, previdenciários e sociais. No momento presente, o desafio da democratização da educação vem se tornando cada vez maior para os povos situados em um contexto sócio-político-econômico semelhante ao do Brasil.

\section{Referências Bibliográficas}

AZEVEDO, Fernando de et alii. Manifesto dos pioneiros da Educação Nova [1932]. Recife: Fundação Joaquim Nabuco/ Massangana, 2010. 122p. (Coleção Educadores). 
FERNANDES, Florestan. Universidade brasileira: reforma ou revolução? São Paulo, AlfaÔmega, 1975.

FERNANDES, Florestan. A Revolução Burguesa no Brasil. $5^{\text {a }}$ ed. São Paulo: editora Globo, 2006.

MARTINS, Racquel Valério. Educação em Direitos Humanos e para a Cidadania Democrática: BRASIL ("um desenvolvimento retrógrado") versus Espanha. Revista do Instituto Brasileiro de Direitos Humanos, v. 19, 09 jun. 2019, p. 265-278, 2019. Disponível em: http://revista.ibdh.org.br/index.php/ibdh Acesso em: 02 jan. 2020.

MARTINS, Racquel Valério; QUINTEIRO, M. Esther Martinéz; CARVALHO, Ana Claudia Campina. Cooperativas de Aprendizagem nas Escolas Rurais. Empreender na prática dos Direitos Humanos. Revista Arma da Crítica, Ano 9, Número 11 maio 2019 - Novo. Disponível em: http://www.armadacritica.ufc.br/ Acesso em: 02 jan. 2020.

MAZZEO, Antônio Carlos. Estado e burguesia no Brasil. Origens da autocracia burguesa. $3^{\mathrm{a}}$ edição. São Paulo: Boitempo, 2015.

MENDES SEGUNDO, Maria das Dores. O Banco Mundial e suas implicações na política de financiamento da educação básica no Brasil: o FUNDEF no centro do debate. 2005. Tese (Doutorado em Educação) - Programa de Pós-Graduação em Educação da Universidade Federal do Ceará, Faculdade de Educação - FACED, Fortaleza.

NAGLE, Jorge. Educação e Sociedade na Primeira República. $3^{\text {a }}$. ed. São Paulo: Editora da Universidade de São Paulo, 2009.

PRADO JÚNIOR, Caio. História Econômica do Brasil. 26ª ed. São Paulo: Brasiliense, 2006. ROMANELli, Otaíza de Oliveira. História da Educação no Brasil: 1930/1973. 40ª . ed. Petrópolis: Vozes, 2014.

SAVIANI, Demerval. Escola e Democracia. 32a . ed. Campinas: Autores Associados, 1999. (Coleção Polêmicas do nosso tempo, v. 5).

SAVIANI, Demerval; DUARTE, Newton (Orgs). Pedagogia histórico-crítica e luta de classes na educação escolar. Campinas: Autores Associados, 2012.

SOUSA JÚNIOR, Justino de. A crise da escola. Fortaleza: Universidade Federal do Ceará, 2014. 